\title{
Relationships Between Weather Conditions, Agronomic Practices, and Fermentation Characteristics with Deoxynivalenol Content in Fresh and Ensiled Maize
}

\author{
M. A. Mansfield, E. D. De Wolf, and G. A. Kuldau, Department of Plant Pathology, The Pennsylvania State Uni- \\ versity, University Park 16802
}

\begin{abstract}
Mansfield, M. A., De Wolf, E. D., and Kuldau, G. A. 2005. Relationships between weather conditions, agronomic practices, and fermentation characteristics with deoxynivalenol content in fresh and ensiled maize. Plant Dis. 89:1151-1157.

The deoxynivalenol (DON) content of maize silage was determined in samples collected at harvest and after ensiling in 2001 and 2002 from 30 to 40 Pennsylvania dairies. Information on cultural practices, hybrid maturity, planting, and harvest date was collected from each site. Sitespecific weather data and a corn development model were used to estimate hybrid development at each site. Correlation analysis was used to assess the relationship between weather data, hybrid development, cultural practices and preharvest DON. Fermentation characteristics (moisture, $\mathrm{pH}$, and so on) of ensiled samples were measured to study their relationship to postharvest DON contamination. No significant difference $(P \leq 0.05)$ was noted between the numbers of samples containing DON in 2001 and 2002, although concentration was higher in 2002 samples. A positive correlation was observed between DON concentration of harvest samples and daily average temperature, minimum temperature, and growing degree day during tasselling, silking, and milk stages. A negative correlation was observed between daily average precipitation at blister stage and DON concentration in harvest samples. Samples from no-till or minimum-till locations had higher DON concentrations than moldboard or mixed-till locations. Harvest samples had higher DON concentration than ensiled samples, suggesting that some physical, chemical, or microbiological changes, resulting from ensiling, may reduce DON in storage.
\end{abstract}

Additional keywords: dairy, Gibberella ear rot, Gibberella zeae

The mycotoxin deoxynivalenol (DON) is one of the most widely reported natural contaminants of maize and other cereals $(36,48)$. Several species of Fusarium produce DON and its acetylated derivatives, but Fusarium graminearum Schwabe is the most commonly isolated DON producer in North America (35). The presence of DON in maize-based feeds, including silage, is associated with animal health problems and poor performance $(9,49,57,58)$, although cattle are less acutely sensitive than other animals (5). However, $F$. graminearum is capable of producing mycotoxins other than DON (15) and often is isolated simultaneously with other mycotoxigenic fungi (3), increasing the risk of synergistic or additive toxic effects on animal consumers (44). To date, no studies have investigated the chronic effects of subacute levels of DON on dairy cattle.

Corresponding author: G. A. Kuldau

E-mail: kuldau@psu.edu

This research was funded in part by agricultural research funds administered by the Pennsylvania Department of Agriculture.

Accepted for publication 17 June 2005.

DOI: 10.1094/PD-89-1151

(C) 2005 The American Phytopathological Society
F. graminearum is a serious pathogen of maize, causing Gibberella ear and stalk rot (in reference to the teleomorph Gibberella zeae (Schwein.) Petch; 37). Much of the research on the relationship between $F$. graminearum and maize has focused on factors that influence infection and colonization in the ear and kernels. However, because maize silage consists of the whole plant, understanding the infection process in vegetative portions of the plant such as the leaves and stalks is also critical. Interestingly, there are reports that the ear and kernels often have significantly lower concentrations of DON compared to the leaves and stalk $(8,23,26)$.

There are several routes by which the fungus gains entry into the plant, including wounds by insects and birds (33), seed transmission (18), and potentially, root colonization (32). The majority of infections occur approximately 6 to 8 days after silk emergence, when ascospores are moved by wind or conidia by splash dispersal $(33,39,47,53)$. Ear infection may lead to colonization in areas adjacent to the initial infection, including the stalk, leaves, and roots $(31,60)$. Stalk colonization has been reported to increase late in the season (59) and is thought to result from an increase in tissue susceptibility as carbohydrates and other nutrients are redirected to developing kernels (10). Premature ripening caused by early-season plant stress also may play a role in stalk infection (59). Stalk infection plays an important role in the epidemiology of Gibberella ear and stalk rot because this tissue is the primary substrate for overwintering and inoculum production the following season (22).

Ideal weather conditions for $F$. graminearum silk infection and spread into the ear are high humidity $(\geq 80 \%)$ and sustained temperatures between 24 and $28^{\circ} \mathrm{C}$ $(30,33,53,56)$. Conversely, there is an association between drought-stressed plants and increased stalk colonization $(10,59)$. Epidemiologically, temperature and moisture appear to be the most influential factors affecting the development of ear and stalk rot $(30,33,53)$. This also appears to be the case for DON biosynthesis both in vitro and in planta $(15,28,42,56)$, which is consistent with reports that DON is a virulence factor in Gibberella rot of maize (16,38). Optimal conditions for production in vitro on maize kernels are temperatures between 28 and $30^{\circ} \mathrm{C}$ and a moisture content of approximately 30 to $40 \%(15,28)$. Vigier et al. (56), with data from fieldinoculated ears, used regression analysis to study DON production in maize and found that higher toxin concentrations were associated with a relative humidity $\geq 80 \%$ during July to September in eastern Canada. Some variation in DON production also is associated with factors such as fungal strain (55), microbial competition (41), and culture substrate (15). A differential response in DON accumulation also has been observed in relation to maize hybrid types (2).

Prevention of Gibberella ear and stalk rot and DON contamination traditionally focuses on agronomic practices that temporally or spatially separate the crop from fungal inoculum (34). The most important source of inoculum for Gibberella ear and stalk rot is crop debris, particularly maize stalk residue, left on the field after harvest (22). The fungus is also pathogenic on cereals such as wheat, barley, and rye (6) and residue from these crops are also inoculum sources $(30,33,53)$. Rotation with a nonhost broadleaf crop temporally separates susceptible plants from inoculum, and several studies have demonstrated that such a rotation sequence decreased incidence and severity of disease and final DON concentration $(27,50)$. Tillage systems that are aggressive in burying crop residue physically separate the crop from inoculum and may serve to reduce disease 
and DON in wheat (7), but this has been an inconsistent trend (33). There also has been considerable focus toward improving host resistance through breeding and genetic engineering; however, to date, these strategies have had limited success or are still in developmental stages (34). Therefore, there is incentive to develop postharvest strategies to control the toxin in storage. When performed correctly, ensiling eliminates $F$. graminearum populations, implying that additional DON production is unlikely to occur as long as anaerobic conditions are maintained (14). However, once DON is formed in the field, neither storage nor ensiling have been found to affect toxin concentration (25). Several bacterial strains show promise in their ability to reduce or eliminate DON $(12,17,51)$, but no attempts have been made to apply them for postharvest DON control. Organic acid application also is reported to reduce some mycotoxin levels in silage, but the effect on DON is not known (19).

Currently, there are no management practices that provide consistent control of DON in maize silage. This results in part from an incomplete understanding of the factors that influence DON production in parts of the plant other than the ear. To compound this problem, many studies utilize artificial inoculation rather than natural infection, which makes them difficult to relate to field conditions. The effect of agronomic practices on DON in maize also is not well understood and few studies have addressed this issue. In response to these concerns, our objective was to investigate how natural DON contamination in maize silage is affected by different agronomic practices, weather conditions, and ensiling. The agronomic practices used to manage the silage in this study were based solely on producers' management decisions, and weather conditions were not under artificial control. It is our hope that this work will improve the current understanding of factors that influence DON in maize silage so that more effective strategies can be developed to control this toxin.

\section{MATERIALS AND METHODS}

Maize silage samples were collected from four regions in Pennsylvania (Fig. 1) in 2001 and 2002 from farms with a history of known or suspected mycotoxin contamination. In all, 32 farms participated in 2001 and 39 in 2002. Samples were collected at harvest and approximately 3 to 6 months after ensiling. Harvest samples consisted of freshly chopped maize that was collected from a mechanical harvester as it made several passes within a field intended for ensiling. Samples of ensiled maize were removed either from several locations at the face of a structure (bunker or trench silo) or as the silage was being emptied from a silo during feed out (upright silo). Sample collection was based on the amount of silage fed per day, with sites feeding 1 to 2 tons collecting samples every other day for 14 days and sites feeding 3 to 4 (or more) tons per day collecting for 7 days consecutively. Both the harvest and ensiled samples were mixed by hand and a 1- to 3-kg portion removed and stored at $-80^{\circ} \mathrm{C}$ until further analysis.

Analysis of the DON content of harvest and ensiled samples from 2001 and 2002 was performed by Cumberland Valley Analytical Services Inc. (CVAS, Haggerstown, MD) using a modified thin-layer chromatography method (54) verified by high-performance liquid chromatography (11). The limit of quantification (the amount of toxin that can be quantified reliably by the method $95 \%$ of the time) for DON in silage was $0.5 \mu \mathrm{g}$ of DON per gram of silage. Fermentation characteristics of ensiled samples, including percent dry matter, $\mathrm{pH}$, ammonia content, and the

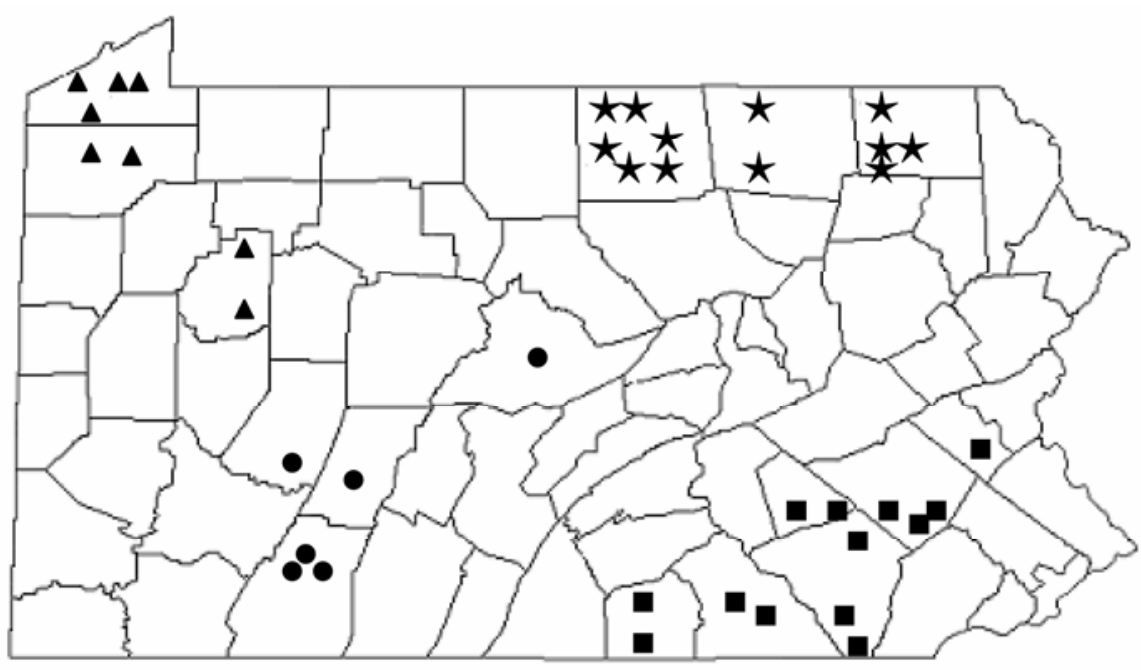

Fig. 1. Relative location of sample dairies in the four major production areas of Pennsylvania. Dairies are represented by region: $\boldsymbol{\Delta}$ in the northwest, $\star$ in the northeast, $\boldsymbol{O}$ in the south central, and $\boldsymbol{\square}$ in the southeast. concentrations of lactic, acetic, proprionic, butyric, and isobutyric acids, also were analyzed by CVAS.

All statistical tests used in the data analysis were performed using a $95 \%$ confidence level. The Pearson Correlation Coefficient was used to examine the relationships between silage fermentation characteristics and DON concentration in the ensiled samples from 2001 and 2002. The Kendall Correlation Coefficient was used to evaluate the relationship between fermentation characteristics and the frequency of DON contamination in ensiled samples (incidence). This nonparametric test was deemed necessary because of the binary nature of the DON incidence data $(1=\mathrm{DON}$ presence and $0=\mathrm{DON}$ absence). These data violated the requirements of the parametric correlation procedure (Pearson's), which assumes normally distributed data and continuous variables. The nonparametric procedure also allowed for the detection of nonlinear relationships. Both correlation coefficients were calculated using the PROC CORR procedure in SAS statistical software (SAS Institute Inc., Cary, NC.).

Using the nonparametric Mann-Whitney test, DON incidence was compared between the 2001 and 2002 growing seasons and between harvest and ensiled samples (Minitab Inc., State College, PA). The nonparametric Kruskal-Wallis test was used to compare DON incidence (2001 and 2002 harvest and ensiled samples) among the four maize silage production regions in Pennsylvania. Nonparametric tests were applied to DON incidence data to avoid violating the assumptions of equivalent parametric tests. DON concentration was compared between samples from the 2001 and 2002 growing seasons and between the harvest and storage samples using the paired $t$ test. DON levels (2001 and 2002 harvest and ensiled samples) among the four regions of Pennsylvania were compared using a general linear model.

ZedX, Inc. (Bellfonte, PA) provided estimated daily weather data for each site using algorithms (29) and the coordinates and elevation of each location. Weather variables included the minimum, maximum, and average temperature, total precipitation, average relative humidity, total wetness hours, growing degree day (base $10^{\circ} \mathrm{C}$ ), accumulated growing degree day (with day 1 beginning at planting date), precipitation minus evaporation, and the accumulated precipitation minus evaporation (with day 1 beginning at the planting date). Using planting date information and hybrid type planted at each farm, ZedX, Inc. provided a daily prediction of hybrid growth during the growing season using a method developed from the work of Allen (1). Prior to data analysis, the daily weather variables for each site were averaged for each growth stage. For example, if silking occurred over a 5-day period at a 
site, 5 days of data for each variable were averaged and the single value used to represent conditions during silking. Growth stages of particular interest included tasselling (VT) through physiological maturity (R6) (45). Pearson's correlation was used to determine the relationship between weather variables during each growth stage and the DON levels in the 2001 and 2002 harvest samples. The relationship between DON incidence in 2001 and 2002 harvest samples and weather variables was assessed using Kendall's correlation.

During silage harvest, information on agronomic practices used to manage the crop was collected. Practices under consideration included whether rotation with a broadleaf crop occurred, the type of tillage system used, whether an inoculant of lactic acid bacteria or an organic acid was added prior to ensiling, and the type of silo used to store the feed. Crop rotation was designated by whether the producer did (rotation $=1$ ) or did not $($ rotation $=0)$ rotate corn with a broadleaf crop. Tillage systems utilized were classified as no till (class 1), minimum till (class 2), moldboard or deep till (class 3), and mixed tillage (class 4), where a variety of systems were used to manage crop residue. No till would be considered the least aggressive system in terms of burying crop residue, followed by minimum tillage, mixed tillage, and finally moldboard tillage, which would bury the most debris. Inoculant use was indicated by use (use $=1$ ) or omission (use $=0$ ) prior to ensiling. Silo type was categorized as upright (type 1), trench or bunker (type 2 ), or a bag silo (type 3 ). Kendall's correlation was used to determine agronomic practices related to DON incidence and levels in harvest and ensiled samples. Practices found to have a relationship to DON incidence or levels were further evaluated with the Tukey-Kramer test to determine differences between categorical levels.

\section{RESULTS}

The incidence of DON contamination in silage samples (harvest and ensiled) was not significantly different between the two growing seasons $(P=0.2644)$. In 2001, $84 \%$ of the total number of samples $(n=$ 62) contained DON, whereas $66 \%$ were contaminated in 2002. Although incidence was not different between seasons, there were significantly higher levels of DON present in 2002 (harvest and ensiled) compared with 2001 ( $P \leq 0.0001$; Fig. 2). The average DON concentration of 2001 (harvest and ensiled) samples was $0.8 \mu \mathrm{g} / \mathrm{g}$ (range: 0 to $3.7 \mu \mathrm{g} / \mathrm{g}$ ), whereas the average for 2002 was $1.1 \mu \mathrm{g} / \mathrm{g}$ (range: 0 to 5.1 $\mu \mathrm{g} / \mathrm{g}$ ). Of the total number of 2002 samples $(n=62), 68 \%$ had higher concentrations of DON than 2001 samples, with $42 \%$ having $\geq 1 \mu \mathrm{g} / \mathrm{g}$ DON than their 2001 counterparts. When DON incidence was compared between harvest and ensiled samples from 2001 and 2002, harvest samples were more frequently contaminated than ensiled samples $(P \leq 0.0001)$. For example, although $75 \%$ of the total number of harvest samples $(n=71)$ contained DON, only $42 \%$ of the ensiled samples were positive. DON concentration also was different between harvest to ensiled $(P \leq 0.0001$; Fig. 3). The average DON concentration of harvest samples (2001 and 2002) was 1.4 $\mu \mathrm{g} / \mathrm{g}$ (range: 0 to $5.1 \mu \mathrm{g} / \mathrm{g}$ ), whereas the average of ensiled samples (2001 and 2002) was $0.6 \mu \mathrm{g} / \mathrm{g}$ (range: 0 to $3.7 \mu \mathrm{g} / \mathrm{g}$ ). In $2001,68 \%$ of the harvest samples had DON at a concentration of $\geq 1 \mu \mathrm{g} / \mathrm{g}$ or more than their ensiled counterparts; whereas, in $2002,39 \%$ of the harvest samples had
DON at $\geq 1 \mu \mathrm{g} / \mathrm{g}$. Neither DON incidence nor concentration was significantly different between the regions for either year $(P$ $=0.4628$ ).

Weather conditions and seasonal plant development. Statewide, both the 2001 and 2002 growing seasons (April to October) had higher than average temperatures. Out of 108 recorded growing seasons, 2001 ranked 53rd warmest and 2002 ranked 6th warmest of the seasons on record (National Climatic Data Center, Ashville, NC). Both seasons also received less than average precipitation, with 2001 and 2002 ranking as the 28th and 24th driest years, respectively.

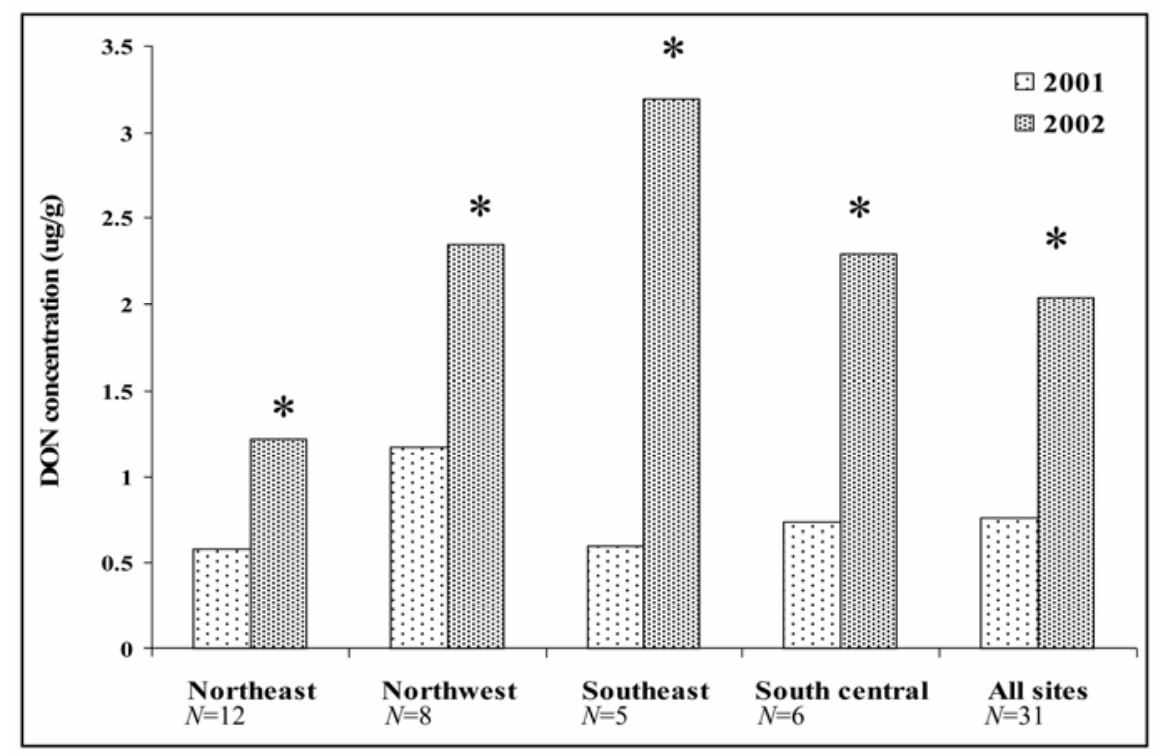

Fig. 2. Average deoxynivalenol (DON) concentration in maize at harvest and after ensiling from 2001 and 2002. Asterisks over 2002 sample bars had significantly higher concentrations of DON than their 2001 sample counterparts.

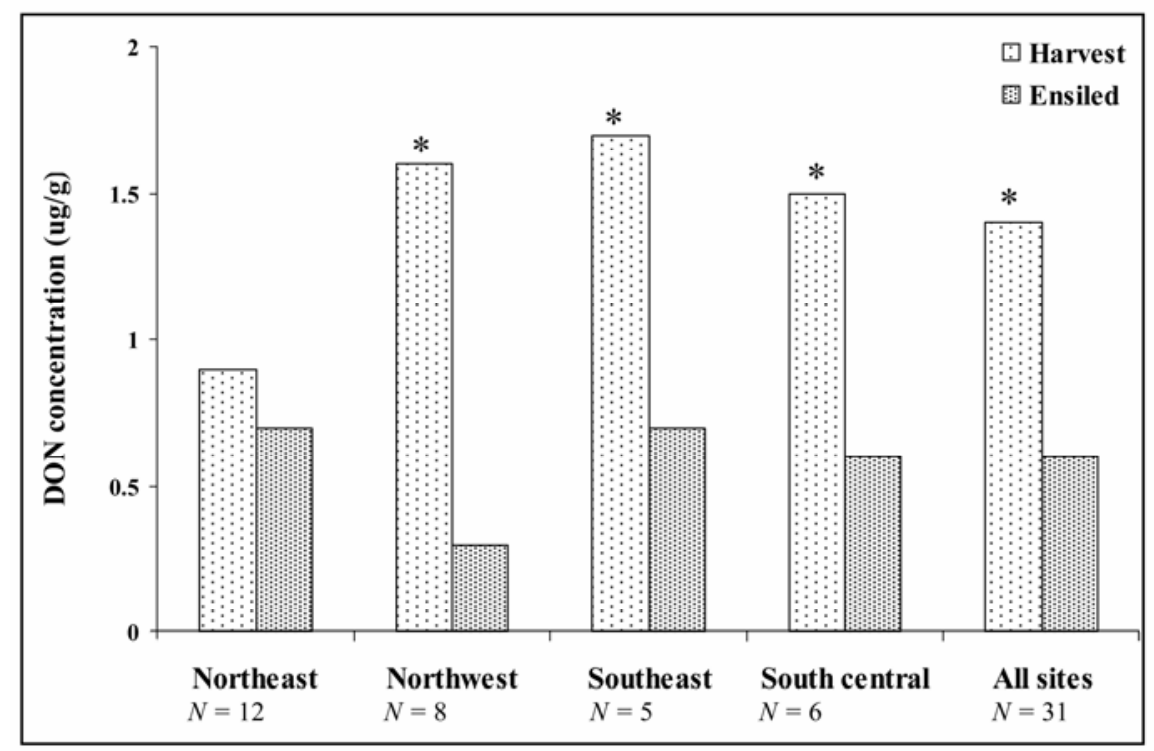

Fig. 3. Average deoxynivalenol (DON) concentration in maize at harvest and after ensiling in 2001 and 2002. Asterisks over harvest sample bars indicate that these samples had significantly higher concentrations of DON than their ensiled counterparts. 
Comparison between the seasons found that the 2002 crop took fewer days to reach several developmental stages compared with 2001, despite the fact that the average planting dates were comparable (2001, day 124 and 2002, day 129 from 1 January; Fig. 4). A paired $t$ test indicated these differences to be significant for tassel (VT, $P=0.013$ ), silking (R1, $P=0.015)$, blister (R2, $P=$ $0.024)$, and milk (R3, $P=0.010)$ stages, with the average harvest maturity in 2001 at dough (R4) stage and in 2002 at dent stage (R5). The recommended stage for silage harvest is physiological maturity (R6; 46).

Temperature and moisture variables during VT, R1, R2, and R3 growth stages had the most significant relationship to DON concentration in 2001 and 2002 harvest samples (Table 1). A positive relationship was observed between DON levels and average daily temperatures during VT, R1, and R3 and a negative relationship between DON and average daily precipitation during R2. Average daily temperatures and minimum daily temperatures during VT, R2, and R3 were higher in 2002 than in 2001, whereas the average daily precipitation, relative humidity, and wetness hours (R2 only) during R2 and R3 were lower in 2002 than in 2001 (Table 1; Fig. 5). No significant relationship was observed between DON levels and weather conditions from R4 to R6 in 2001 and 2002.

Agronomic practices. Correlation analysis between agronomic practices and DON incidence and levels in harvest and

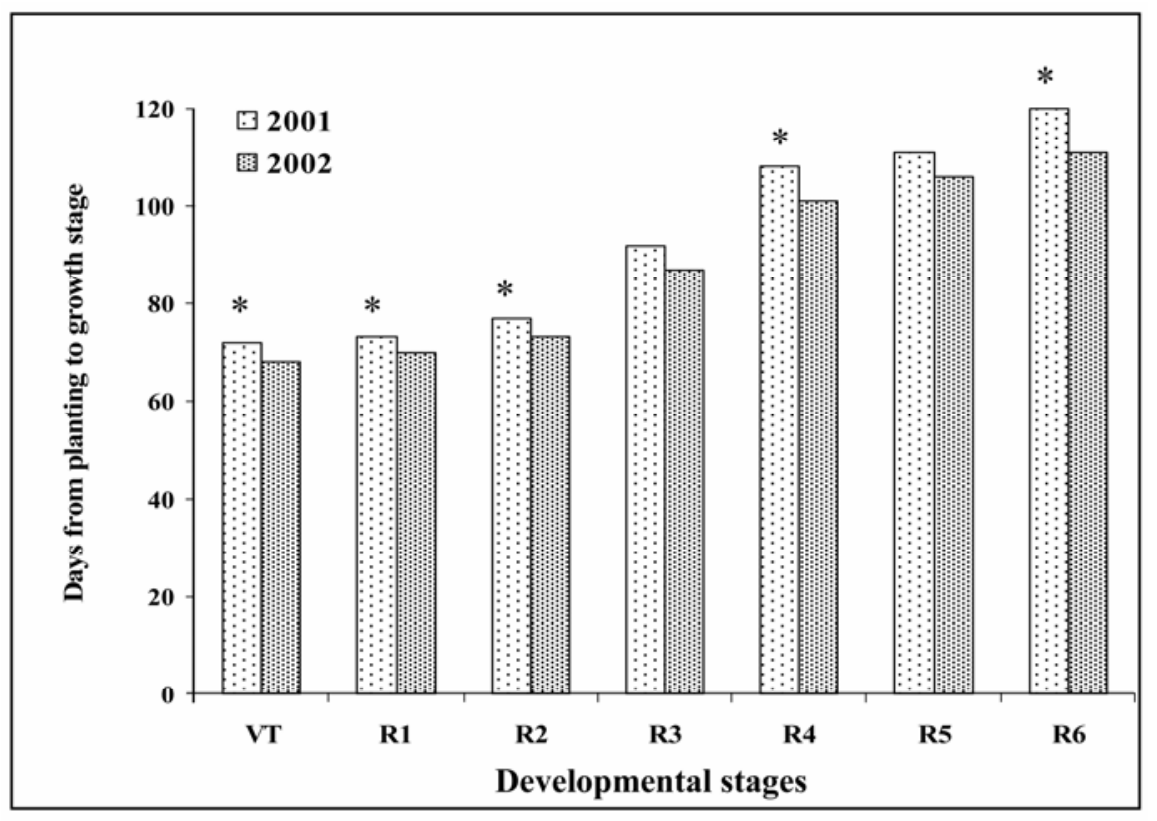

Fig. 4. Number of days in 2001 and 2002 from the planting date to each developmental stage considered in the study. Asterisks over 2001 bars indicate that it took significantly more days to reach a growth stage compared with the 2002 crop. Developmental stages: VT = tasselling, R1 = silking, R2 = blister, R3 = milk, R4 = dough, R5 = dent, and R6 = physiological maturity (45). ensiled samples from 2001 and 2002 revealed that only tillage type had a significant affect $(P=0.0108)$ and only on DON levels. Neither crop rotation (harvest samples), additive use before ensiling (ensiled samples), nor silo type (ensiled samples) had an effect on DON incidence or levels. Although tillage type did not significantly affect DON incidence $(P=0.960)$, it did impact DON concentration $(P=0.031$; Fig. 6). The average DON concentration in samples (harvest and ensiled from 2001 and 2002) managed by different tillage systems was as follows: no till, $2.4 \mu \mathrm{g} / \mathrm{g}$ (range: 0 to $5.1 \mu \mathrm{g} / \mathrm{g}$ ); minimum till, 1.7 $\mu \mathrm{g} / \mathrm{g}$ (range: 0 to $5.1 \mu \mathrm{g} / \mathrm{g}$ ); mixed till, 1.1 $\mu \mathrm{g} / \mathrm{g}$ (range: 0 to $4.3 \mu \mathrm{g} / \mathrm{g}$ ); and moldboard till, $0.6 \mu \mathrm{g} / \mathrm{g}$ (range: 0 to $1.8 \mu \mathrm{g} / \mathrm{g}$ ). Comparison of DON levels between samples under different tillage systems revealed that samples from no-till sites had higher DON concentrations than moldboard (deep-tillage) or mixed-tillage samples (Fig. 6). The average DON content from no-till sites was approximately four times higher than samples from moldboard sites and twice as high as samples from mixedtill sites. Although the average DON concentration in minimum-till samples was lower than in no-till by an average of 0.7 $\mu \mathrm{g} / \mathrm{g}$, the difference was not significant.

Forage quality. Fermentation analysis on percent dry matter, $\mathrm{pH}$, ammonia content, lactic acid, acetic, proprionic, butyric, and isobutyric acid content found that the majority of ensiled samples (2001 and 2002) were in the range of what is considered normal for maize silage (46). No relationship was observed between percent dry matter, $\mathrm{pH}$, ammonia content, lactic acid, acetic, proprionic, butyric, and isobutyric acid content and DON incidence or DON levels in the samples.

\section{DISCUSSION}

The levels and frequency of DON contamination in maize silage from this study

Table 1. Relationship between deoxynivalenol content in maize at harvest and weather conditions during select maize developmental stages in 2001 and 2002

\begin{tabular}{|c|c|c|c|c|}
\hline \multirow[b]{2}{*}{ Growth stage, weatherb } & \multicolumn{2}{|c|}{ Average (range) ${ }^{\mathrm{a}}$} & \multirow[b]{2}{*}{ Corr. coef. ${ }^{\mathrm{c}}$} & \multirow[b]{2}{*}{$P$ value } \\
\hline & 2001 & 2002 & & \\
\hline \multicolumn{5}{|l|}{ VT } \\
\hline Min. temp. $\left({ }^{\circ} \mathrm{C}\right)$ & $17.4(14.4-20.1)$ & $18.3(11.8-21.8)$ & 0.395 & 0.001 \\
\hline Ave. temp. $\left({ }^{\circ} \mathrm{C}\right)$ & $22.8(20.1-25.2)$ & $23.6(18.7-26.6)$ & 0.324 & 0.006 \\
\hline AGDD & $3,820.1(3,858.6-4,294.5)$ & $4,085.7(3,605.8-4,767.0)$ & 0.332 & 0.004 \\
\hline \multicolumn{5}{|c|}{ 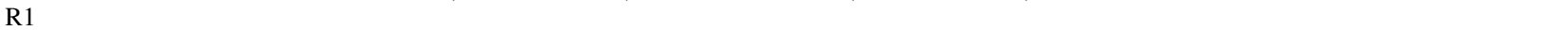 } \\
\hline AGDD & $3,996.0(3,758.3-4,487.8)$ & $4,267.3(3,751.5-4,966.0)$ & 0.324 & 0.005 \\
\hline \multicolumn{5}{|c|}{ 然 } \\
\hline Precipitation $(\mathrm{cm})$ & $0.26(0.14-0.53)$ & $0.12(0.05-0.23)$ & -0.402 & $>0.0001$ \\
\hline $\mathrm{RH}(\%)$ & $73.7(69.3-77.8)$ & $68.6(60.2-76.9)$ & -0.378 & 0.001 \\
\hline WH (h) & $12.4(9.7-16.2)$ & $7.1(3.2-14.3)$ & -0.446 & $>0.0001$ \\
\hline \multicolumn{5}{|l|}{ R3 } \\
\hline Min. temp. $\left({ }^{\circ} \mathrm{C}\right)$ & $13.1(8.2-20.1)$ & $16.3(11.5-21.1)$ & 0.257 & 0.030 \\
\hline Ave. temp. $\left({ }^{\circ} \mathrm{C}\right)$ & $18.6(13.7-24.5)$ & $22.0(17.7-27.1)$ & 0.235 & 0.047 \\
\hline AGDD & $5,015.6(4,653.3-5,488.0)$ & $5,222.9(4,550.3-6,036.0)$ & 0.235 & 0.047 \\
\hline
\end{tabular}

\footnotetext{
${ }^{a}$ Data shown are the averaged values for each growing stage.

${ }^{\mathrm{b}}$ Growth stages: $\mathrm{VT}=$ tassel, $\mathrm{R} 1=$ silking, $\mathrm{R} 2=$ blister, and $\mathrm{R} 3=$ milk $(45)$; weather variables: Min. temp. $=$ minimum temperature, Ave. temp. $=$ average temperature, $\mathrm{AGDD}=$ accumulated growing degree day (base of $50^{\circ} \mathrm{F}$ ), $\mathrm{RH}=$ relative humidity, and $\mathrm{WH}=$ wetness hours.
}

${ }^{c}$ Pearson's correlation coefficients were calculated for the combined data set from 2001 and $2002(n=124$ samples). 
are comparable to those reported for maize grain and silage samples from other North American studies $(36,48,61)$. In general, the concentrations of DON encountered in this study were not high enough to warrant excessive concern for dairy cattle health. We did find it surprising that DON levels in 2002 were significantly higher than in 2001, because this season was a drought year. Numerous studies have demonstrated that warm temperatures in combination with frequent precipitation are favorable for $F$. graminearum infection and colonization and DON production in maize $(30,40,52,53,56)$. However, the observation that DON concentration is higher in warm, wet years versus hot, dry seasons is based on studies of the ear and grain, not the whole plant $(24,40-42,52,56)$. Although temperatures in 2002 were closer to the optimal DON production temperature of $28^{\circ} \mathrm{C}(15,28)$, the moisture availability in this season was less than in 2001, particularly during the R2 and R3 stages of development. Dodd (10) noted that there was an association between drought stress and increased stalk rot. Therefore, drought stress in the 2002 crop may have resulted in increased fungal colonization in the stalk and subsequently, higher levels of DON compared with 2001. We also observed that the 2002 crop matured more quickly but remained in the field an equal amount of time as 2001 silage. Several studies have found that premature maturation and a delay in harvest are associated with greater disease severity and higher final DON concentration $(10,24,59)$. However, because plants were not evaluated for fungal colonization, it is difficult to say that the conditions we observed are the only elements contributing to higher DON in 2002.

Our observation that temperature and moisture were important factors in influencing DON concentration in maize agrees with findings reported by other researchers (40-42,52,56). Although temperature (within the temperature range considered in this study) had a positive relationship to DON, indicating that, as temperature in-

\section{A DON concentration}

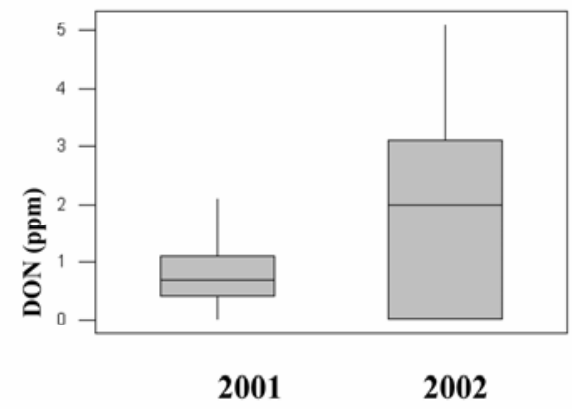

\section{B. VT Tasselling}
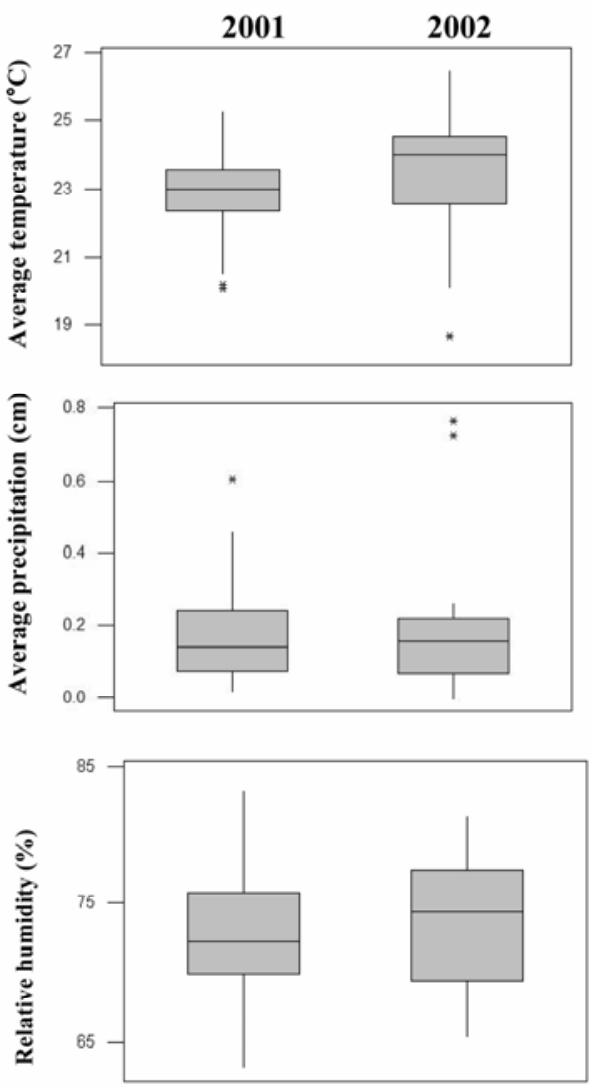

C. R2 Blister
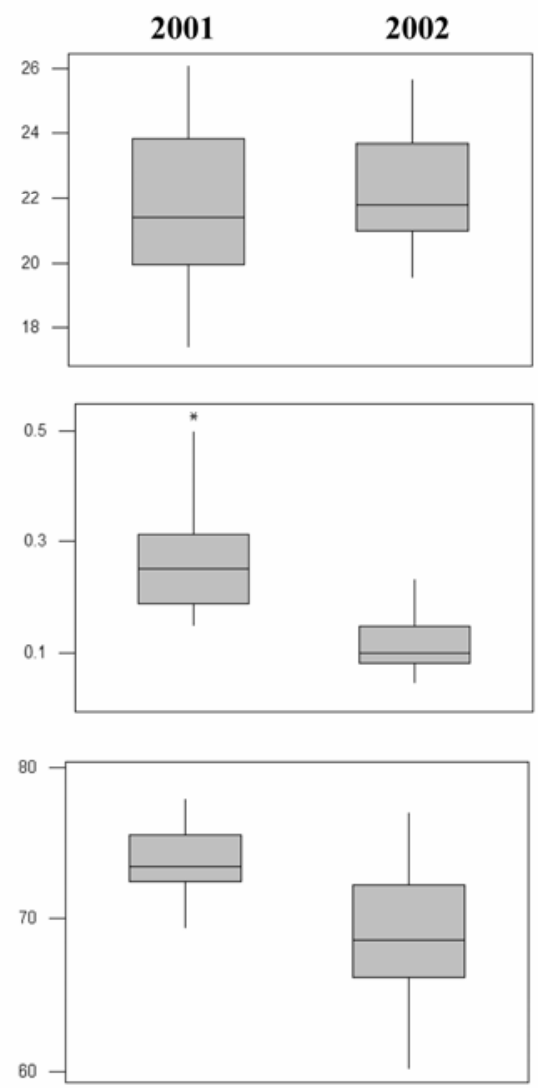

D. R3 Milk
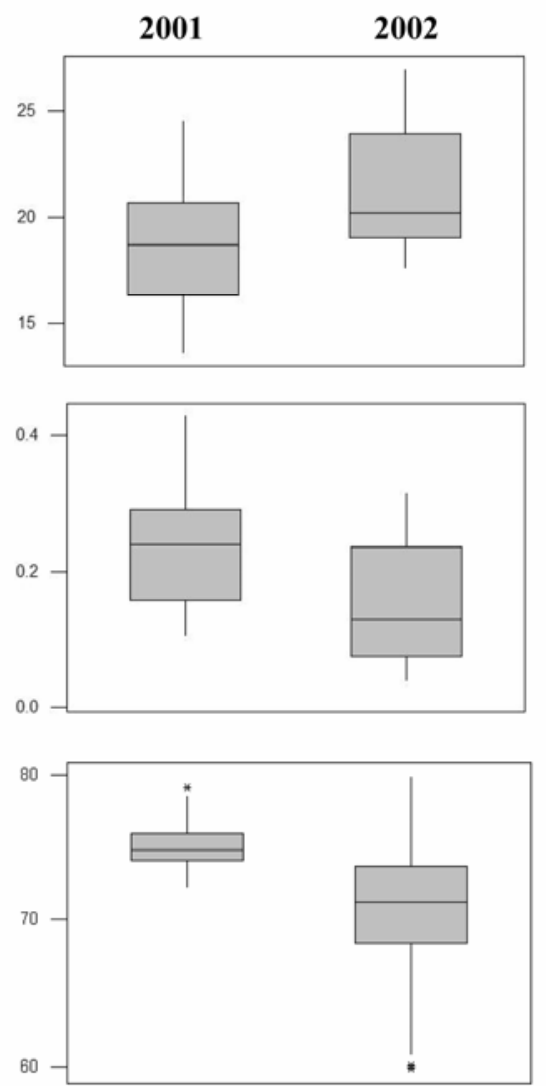

Fig. 5. A, Box plot comparing deoxynivalenol (DON) concentrations in the 2001 and 2002 growing seasons. DON concentration is expressed in parts per million (ppm) which is equivalent to micrograms of DON per grams of silage. Box plots compare the averages and ranges of weather variables between 2001 and 2002 seasons during the B, tasselling (VT), C, blister (R2), and D, milk (R3) growth stages. 
creased, DON concentration did as well, moisture had a negative affect in that, as moisture decreased, DON increased. These relationships again reflect the idea that warm temperatures and decreased moisture availability may have resulted in plant stress, increased fungal colonization, and greater DON accumulation, rather than suggesting that warm temperatures and low moisture availability are directly responsible for increased DON production in planta. also may play an important role in final DON concentration, because weather conditions during tassel (R1) to milk (R3) had the strongest correlation to DON levels. During these stages, the majority of plant nutrients are diverted to embryo and kernel development, somewhat to the detriment of vegetative tissue like the stalk. Therefore, stressful conditions during these developmental periods may have an additive effect on stalk susceptibility to $F$. graminearum infection.

Although weather conditions likely have the greatest influence on DON in maize silage, according to our findings and those of previous research $(40-43,52)$, some affect also may be attributed to agronomic practices, including crop rotation and tillage type. Studies with wheat found that less DON was present in the grain when it was grown after a broadleaf crop then when it was grown after wheat or maize (50). Ear rot severity in maize decreased when rotation with a broadleaf crop was incorporated in corn production (27), but the implications for DON accumulation under noninoculated and nonirrigated conditions are not clear $(34,43)$. The results of this investigation indicate that crop rotation with a broadleaf crop did not signifi-
The timing of potential drought stress

cantly impact DON contamination of maize silage. However, few sites included in this study practiced crop rotation, limiting our ability to detect differences. Further research is needed to clarify the influence of crop rotation on DON contamination.

In this study, we observed that, although tillage type had no effect on DON incidence, it did influence DON concentration. This is somewhat surprising because one might expect that burying crop debris would reduce disease and DON incidence rather than DON concentration. Flett et al. (13) found no relationship between tillage practices and severity of Gibberella ear rot; however, the impact on DON accumulation was not considered. Synthesis of previous reports with the current study suggests that deep tillage alone is unlikely to adequately reduce DON incidence and concentration. Although we observed that silage from moldboard-tilled sites had the lowest DON concentration, deep tillage is known to reduce soil moisture retention (4). As such, deep tillage may exacerbate the mycotoxin situation by intensifying drought stress and predisposing the crop to stalk rot. Until the impact of tillage on DON in maize is more fully understood, an approach to mycotoxin management that integrates disease control strategies, including tillage, crop rotation, and host resistance, along with other critical factors such as soil conservation and farm financial considerations, is likely to be the most successful in the future.

In contrast to previous reports that DON concentration does not change after ensiling (25), we found that DON concentration was lower in ensiled samples compared with those collected at harvest. When we evaluated the relationship between physi-

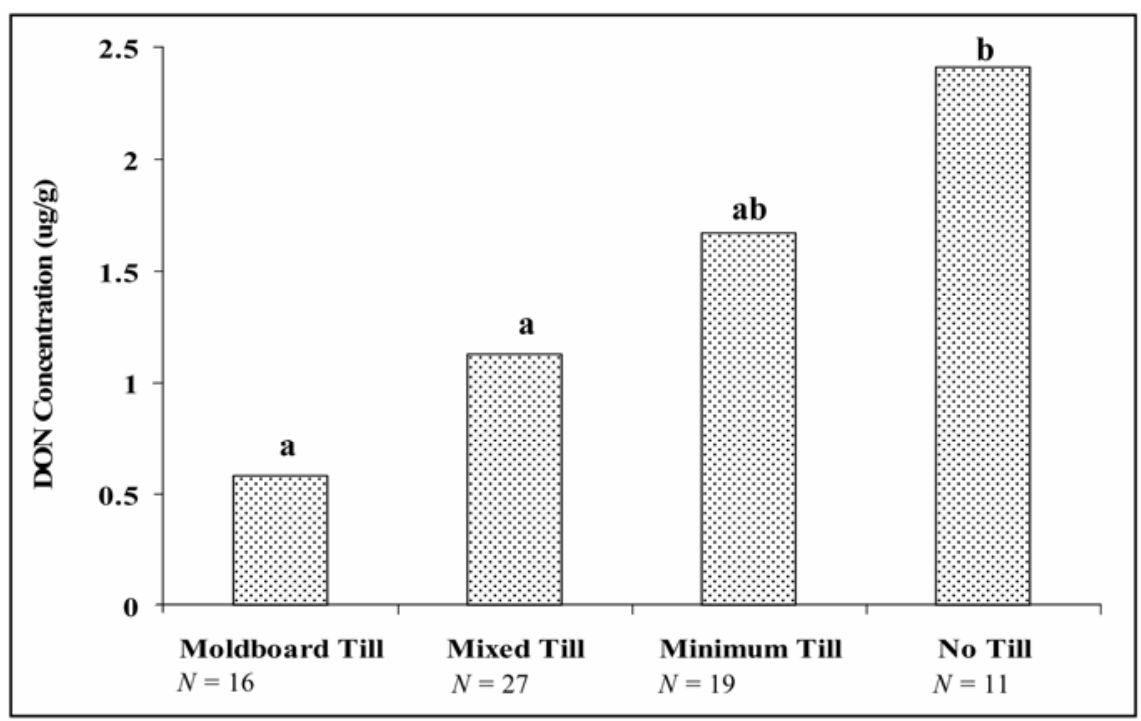

Fig. 6. Average deoxynivalenol (DON) concentration in 2001 and 2002 silage samples managed under different tillage systems. Mixed tillage refers to systems where more than one tillage type was used. Letters over bars indicate significant differences in DON concentration between tillage systems detected by the Tukey-Kramer test. Bars marked by the same letter are not significantly different. cal and chemical characteristics of ensiled samples, we found that none of the factors considered had a significant affect on DON concentration. Therefore, we think that toxin reduction may be due to the activity of silage microflora. Several bacteria have been found to degrade or bind DON to their cell membranes $(12,17,51)$ when cultured in vitro. Interestingly, microbial degradation also appears to take place in the rumen of cattle and other animals $(20,21)$, and it is possible that animals acquire these organisms by consuming silage. Our findings lend credence to the idea that DON may be managed in a postharvest situation. Future work potentially should focus on isolating organisms in silage that can degrade DON and determining how their activity can be enhanced in contaminated silages.

To our knowledge, this is the first study to investigate the combination of weather conditions, agronomic practices, and ensiling on natural DON contamination at a large number of locations. Although managing preharvest DON contamination may be difficult due to the large and relatively uncontrollable affect of weather, utilizing a combination of pre- and postharvest control strategies may prove to be fruitful. Likewise, future studies should focus on improving our understanding of DON accumulation in the whole plant and determine whether postharvest toxin degradation can be enhanced in maize silage.

\section{ACKNOWLEDGMENTS}

We thank participating dairy producers as well as Pennsylvania State University Extension Educators and representatives from Agway, Inc., Pennfield, Inc., and E. M. Brown and Sons, Inc. for providing us with interested participants; J. Molineros, B. Dombroski, and N. Zitomer for statistical and technical assistance; and G. Moorman and G. Roth for critical review of this manuscript.

\section{LITERATURE CITED}

1. Allen, J. C. 1976. A modified sine wave method for calculating degree days. Environ. Entomol. 5:338-396.

2. Atlin, G. N., Enerson, P. M., McGirr, L. G., and Hunter, R. B. 1983. Gibberella ear rot development and zearalenone and vomitoxin production as affected by maize genotype and Gibberella zeae strain. Can. J. Plant Sci. 63:847-853.

3. Baath, H., Knabe, O., and Lepom, P. 1990. Occurrence of Fusarium species and their mycotoxins in maize silage. Studies on the Fusarium infestation of maize silage plants. Arch. Anim. Nutr. 40:397-405.

4. Baily, K. L., and Duczek, L. J. 1996. Managing cereal diseases under reduced tillage. Can. J. Plant Pathol. 18:159-167.

5. Charmley, E., Trenholm, H. L., Thompson, B K., Vudathala, D., Nicholson, J. W. G., Prelusky, D. B., and Charmley, L. L. 1993. Influence of level of deoxynivalenol in the diet of dairy cows on feed intake, milk production, and its composition. J. Dairy Sci. 76:3580-3587.

6. Chelkowski, J. 1989. Formation of mycotoxins produced by Fusarium in heads of wheat, triticale, and rye. Pages 63-84 in: Fusarium Mycotoxins, Taxonomy, and Pathogenicity. J. Chelkowski, ed. Elsevier, Amsterdam.

7. Dill-Macky, R., and Jones, R. K. 2000. The effect of previous crop residues and tillage on 
Fusarium head blight of wheat. Plant Dis. 84:71-76.

8. Di Menna, M. E., Lauren, D. R., and Hardacre, A. 1997. Fusaria and Fusarium toxins in New Zealand maize plants. Mycopathologia 139:165-173.

9. D'Mello, J. P. F., Placinta, C. M., and MacDonald, A. M. C. 1999. Fusarium mycotoxins: a review of global implications for animal health, welfare, and productivity. Anim. Feed Sci. Technol. 80:183-205.

10. Dodd, J. L. 1980. The role of plant stresses in the development of corn stalk rots. Plant Dis. 64:533-537.

11. Ehrlich, K. C., Lee, L. S., and Ciegler, A. 1983. A simple, sensitive method for detection of vomitoxin (deoxynivalenol) using reverse phase, high performance liquid chromatography. J. Liq. Chromatogr. 6:833-843.

12. El-Nezami, H. S., Chrevatidis, A., Auriola, S., Salimen, S., and Mykkanen, H. 2002. Removal of common Fusarium toxins in vitro by strains of Lactobacillus and Proprionibacterium. Food Addit. Contam. 19:680-686.

13. Flett, B. C., McLaren, N. W., and Wehner, F. C. 1998. Incidence of ear rot pathogens under alternating corn tillage practices. Plant Dis. 82:781-784.

14. Golosov, I. M., Boltushkin, A. N., and Kovalskaia, M. G. 1967. The viability of the genus Fusarium in silage. Veterinariia 44:98-100.

15. Greenhalgh, R., Neish, G. A., and Miller, J. D. 1983. Deoxynivalenol, acetyl deoxynivalenol and zearalenone production by Canadian isolates of Fusarium graminearum on solid substrates. Appl. Environ. Microbiol. 46:625-629.

16. Harris, L. J., Desjardins, A. E., Plattner, R. D., Nicholson, P., Butler, G., Young, J. C., Weston, G., Proctor, R. H., and Hohn, T. M. 1999. Possible role of trichothecene mycotoxins in virulence of Fusarium graminearum on maize. Plant Dis. 83:954-960.

17. He, P., Young, L. G., and Forsberg, C. 1992. Microbial transformation of deoxynivalenol (vomitoxin). Appl. Environ. Microbiol. 58:3857-3863

18. Kabeere, F., Hampton, J. G., and Hill, M. J. 1997. Transmission of Fusarium graminearum (Schwabe) from maize seeds to seedlings. Seed Sci. Technol. 25:245-252.

19. Kallella, K., and Saastamoinen, I. 1981. Decomposition of the Fusarium graminearum toxin zearalenone in storage conditions. Nord. Veterinaermed. 33:454-460.

20. Kiessling, K. H., Pettersson, H., Sandholm, K., and Olsen, M. 1984. Metabolism of aflatoxin, ochratoxin, zearalenone, and three trichothecenes by intact rumen fluid, rumen protozoa, and rumen bacteria. Appl. Environ. Microbiol. 47:1070-1073

21. King, R. R., McQueen, R. E., Levesque, D., and Greenhalgh, R. 1984. Transformation of deoxynivalenol (vomitoxin) by rumen microorganisms. J. Agric. Food Chem. 32:11811183.

22. Konga, E. B., and Sutton, J. C. 1988. Inoculum production and survival of Gibberella zeae in maize and wheat residues. Can. J. Plant Pathol. 10:232-239.

23. Lauren, D. R., and Di Menna, M. E. 1999. Fusaria and Fusarium mycotoxins in leaves and ears of maize plants 2 . A time course study made in the Waikato region, New Zealand, in 1997. N. Z. J. Crop Hortic. Sci. 27:215-223.

24. Lauren, D. R., Jensen, D. J., Smith, W. A., Dow, B. W., and Saver, S. T. 1996. Mycotoxins in New Zealand maize: a study of some factors influencing contamination levels in grain. $\mathrm{N}$. Z.. J. Crop Hortic. Sci. 24:13-20.

25. Lepom, P., Knabe, O., and Baath, H. 1991. Occurrence of Fusarium spp., and their mycotoxins in maize; formation of deoxynivalenol (DON) in a maize plot artificially inocu- lated with Fusarium culrmorum and the influence of ensiling on the stability of DON formed. Arch. Anim. Nutr. 40:1005-1012.

26. Lew, H., Adler, A., and Edinger, W. 1997. Dynamics of the Fusarium toxin distribution in maize plants affected by stalk rot. Cereal Res. Commun. 25:467-470.

27. Lipps, P. E., and Deep, I. W. 1991. Influence of tillage and crop rotation on yield, stalk rot, and recovery of Fusarium and Trichoderma spp. from corn. Plant Dis. 75:828-833.

28. Llorens, A., Mateo, R., Hinojo, M. J., ValleAlgara, F. M., and Jimenez, M. 2004. Influence of environmental factors on the biosynthesis of type B trichothecenes by isolates of Fusarium spp. from Spanish crops. Int. J. Food Microbiol. 94:43-54.

29. Magarey, R. D., Seem, R. C., Russo, J. M., Zack, J. W., Waight, K. T., Travis, J. W., and Oudemans, P. V. 2001. Site-specific weather information without on-site sensors. Plant Dis. 85:1216-1226.

30. Miller, J. D. 1994. Epidemiology of Fusarium diseases of cereals. Pages 19-36 in Mycotoxins in Grain: Compounds other than Aflatoxin. J. D. Miller and H. L. Trenholm, eds. Eagan Press, St. Paul, MN

31. Miller, J. D., Young, J. C., and Trenholm, H. L. 1983. Fusarium toxins in field corn I: time course of fungal growth and production of deoxynivalenol and other mycotoxins. Can. J. Bot. 61:3080-3087.

32. Moreno-Gonzalez, J., Ares, A. J. L., Ferro, A. R., and Ramirez, L. C. 2004. Genetic and statistical models for estimating genetic parameters of maize seedling resistance to Fusarium graminearum Schwabe root rot. Euphytica 137:55-61.

33. Munkvold, G. P. 2003. Epidemiology of Fusarium diseases and their mycotoxins in maize. Eur. J. Plant Pathol. 109:707-713.

34. Munkvold, G. P. 2003. Cultural and genetic approaches to managing mycotoxins in maize silage. Annu. Rev. Phytopathol. 41:99-116.

35. O'Donnell, K. Kistler, H. C., Tacke, B. K., and Casper, H. H. 2000. Gene genealogies reveal global phylogeographic structure and reproductive isolation among lineages of Fusarium graminearum the fungus causing wheat scab. PNAS 97:7905-7910.

36. Park, J. J., Smalley, E. B., and Chu, F. S. 1996. Natural occurrence of Fusarium mycotoxins in field samples from the 1992 Wisconsin corn crop. Appl. Environ. Microbiol. 62:1642-1648.

37. Payne, G. A. 1999. Compendium of Corn Diseases, 3rd ed. D. G. White, ed. American Phytopathological Society Press, St. Paul, MN.

38. Proctor, R. J., Hohn, T, M., and McCormick, S P. 1995. Reduced virulence of Gibberella zeae caused by disruption of a trichothecene toxin biosynthetic gene. Mol. Plant-Microbe Interact. 8:593-601.

39. Reid, L. M., Bolton, A. T., Hamilton, R. I., Woldemariam, T., and Mather, D. E. 1992. Effect of silk age on resistance of maize to Fusarium graminearum. Can. J. Plant Pathol. 14:293-298.

40. Reid, L. M., Mather, D. E., and Hamilton, R. I. 1996. Distribution of deoxynivalenol in Fusarium graminearum infected maize ears. Phytopathology 88:110-114.

41. Reid, L. M., Nicol, R. W., Ouellet, T., Savard, M., Miller, J. D., Young, J. C., Steward, D. W., and Shaafsma, A. W. 1999. Interaction of Fusarium graminearum and Fusarium moniliforme in maize ears: disease progress, fungal biomass and mycotoxin accumulation. Phytopathology 89:1028-1037.

42. Reid, L. M., and Sinha, R. C. 1998. Maize maturity and the development of Gibberella ear rot symptoms and deoxynivalenol after inoculation. Eur. J. Plant Pathol. 104:147-154

43. Reid, L. M., Zhu, X., and Ma, B. L. 2001.
Crop rotation and nitrogen effects on maize susceptibility to Gibberella (Fusarium graminearum) ear rot. Crop Soil. 237:1-14.

44. Riley, R. T. 1998. Mechanistic interactions of mycotoxins: theoretical considerations. Pages 227-253 in: Mycotoxins in Agriculture and Food Safety. K. K. Sinha and D. Bhatnagar, eds. Marcel Dekker, Inc., New York.

45. Ritchie, S. W., and Benson, G. O. 1993. How a corn plant grows. Special Report Number 48 Iowa State University Science and Technology Cooperative Extension Service. Ames.

46. Roth, G. W., and Adams, R. S. 2001. Corn silage production and management. Agronomy Facts 18. Pennsylvania Cooperative Extension and the Pennsylvania State University, University Park.

47. Schmale, D. G., and Bergstrom, G. C. 2004. Spore deposition of the ear rot pathogen, Gib berella zeae, inside corn canopies. Can. J. Plant Pathol. 26:591-595.

48. Scott, P. M. 1997. Multi-year monitoring of Canadian grains and grain-based foods for trichothecenes and zearalenone. Food Addit. Contam. 14:333-339.

49. Scudamore, K. A., and Livesey, C. T. 1998. Review: Occurrence and significance of mycotoxins in forage crops and silage. J. Sci. Food Agric. 77:1-17.

50. Shaafsma, A. W., Illincic-Tamburic, L., Miller, J. D., and Hooker, D. C. 2001. Agronomic considerations for reducing deoxynivalenol in wheat grain. Can. J. Plant Pathol. 23:279-285.

51. Shima, J., Takase, S., Takahashi, Y., Iwai, Y., Fujimoto, H., Yamazaki, M., and Ochi, K. 1997. Novel detoxification of the trichothecene mycotoxin deoxynivalenol by a soil bacterium isolated by enrichment culture. Appl. Environ. Microbiol. 63:3825-3830.

52. Stewart, D. W., Reid, L. M., Nicol, R. W., and Shaafsma, A. W. 2002. A mathematical simulation of the growth of Fusarium in maize ears after artificial inoculation. Phytopathology 92:534-541

53. Sutton, J. C. 1982. Epidemiology of wheat head blight and maize ear rot caused by Fusarium graminearum. Can. J. Plant Pathol. 4:195-209.

54. Trucksess, M. W., Nesheim, S., and Eppley, R. M. 1984. Thin layer chromatographic determination of deoxynivalenol in wheat and corn. JAOAC 67:40-43.

55. Vesonder, R. F., Ellis, J. J., Kwolek, W. F., and Demarini, D. 1982. Production of vomitoxin on corn by Fusarium graminearum NRRL 5883 and Fusarium roseum NRRL 6101. Appl. Environ. Microbiol. 43:967-970.

56. Vigier, B., Reid, L. M., Dwyer, L. M., Stewart, D. W., Sinha, R. C., Arnason, J. T., and Butler, G. 2001. Maize resistance to Gibberella ear rot: symptoms, deoxynivalenol and yield. Can J. Plant Pathol. 23:99-105.

57. Whitlow, L. W., Nebel, R. L., and Hagler, W. M. 1994. The association of DON in grain with milk production loss in dairy cows. Pages 131-139 in: Biodeterioration Research 4. G. C. Llewellyn, W. V. Dashek, and C. E. O'Rear, eds. Plenum Press, New York

58. Wilkinson, J. M. 1999. Silage and animal health. Nat. Toxins 7:221-232

59. Windels, C. E., and Kommendahl, T. 1984 Late-season colonization and survival of Fusarium graminearum group II in corn stalks in Minnesota. Plant Dis. 68:791-793.

60. Young, J. C., and Miller, J. D. 1985. Appearance of fungus, ergosterol, and Fusarium mycotoxins in the husk, axial stem and stalk after ear inoculation of field corn. Can. J. Plant Sci. 65:47-53.

61. Yu, W., Yu, F. Y., Undersander, D. J., and Chu, F. S. 1999. Immunoassays of selected mycotoxins in hay, silage, and mixed feed. Food Agric. Immun. 11:307-319. 